Kajian Potensi Penyuluhan Sebagai Upaya Meningkatkan Pengetahuan Masyarakat Desa Ngadas mengenai Tumbuhan obat

\title{
Study of Potential Extension For Improving Knowledge Society in Ngadas Village about Medicinal plants
}

\author{
Hajmia Guswika $^{1}$, Suhadi $^{2}$, Sri Endah Indriwati ${ }^{2}$ \\ ${ }^{1}$ Program studi S2 Biologi Universitas Negeri Malang, \\ 2 Jurusan Biologi, FMIPA, Universitas Negeri Malang \\ *Email: hajmiaguswika@yahoo.com
}

\begin{abstract}
Abstrak
Pengetahuan masyarakat desa Ngadas mengenai tumbuhan obat mulai luntur, sebagaian besar masyarakat tidak mengetahui tumbuhan yang dapat dimanfaatkan sebagai obat di lingkungan sekitar. Sedangkan, pengobatan dengan memanfaatkan tumbuhan merupakan pengobatan tradisional yang telah menjadi warisan budaya yang harus dilestarikan dan telah direkomendasikan oleh WHO sebagai upaya back to nature untuk pemeliharaan kesehatan masyarakat, pencegahan dan pengobatan penyakit. Tumbuhan liar yang berpotensi sebagai obat di desa Ngadas cukup besar contohnya seperti seperti adas, ajeran, akasia duri, anting-anting, alang-alang, patikan kebo, pegagan, semanggi gunung, kersen, krisan, kecubung gunung, tempuyung, dsb. Tujuan dari penulisan artikel ini adalah untuk mengkaji potensi dari penyuluhan sebagai upaya dalam meningkatkan pengetahuan masyarakat. Metode yang digunakan adalah studi literatur dari berberapa jurnal yang meneliti tentang upaya penyuluhan dalam meningkatkan pengetahuan masyarakat. Berdasarkan data yang diperoleh dari studi literatur, kegiatan penyuluhan terbukti berpotensi dalam meningkatkan pengetahuan masyarakat. Maka dari itu perlu dilakukan penyuluhan sebagai upaya memberikan informasi mengenai potensi tumbuhan obat yang terdapat di desa Ngadas.
\end{abstract}

Kata kunci: Pengetahuan, Tumbuhan obat, Penyuluhan

\begin{abstract}
Society knowledge in Ngadas village about medicinal plants began to fade, as people do not know the plants that can be consume as a drug around them. However, the treatment by plant utilizing is a traditional medicine that has become a cultural heritage that should be conserved and has been recommended by the WHO as the effort back to nature for the maintenance of public health, prevention and treatment of disease. Wild plant that has potential as a drug in the village Ngadas big enough examples adas, ajeran, akasia duri, anting-anting, alang-alang, patikan kebo, pegagan, semanggi gunung, kersen, krisan, kecubung gunung, tempuyung, etc. The purpose of writing this article is to examine the potential of extension as a efforts on improving knowledge of society. The method used is to review literature of some journal that examines the educational efforts to improve public knowledge. Based on data obtained from reviewing the literature, extension activities proved potentially in increasing knowledge of society. Thus it is needed to do extension in an effort to provide information on the potential of medicinal plants in the Ngadas villages.
\end{abstract}

Key words: Knowledge, medicinal plant, extention

\section{PENDAHULUAN}

Desa Ngadas merupakan suatu wilayah tertinggi di kabupaten Malang berada di dalam area teritorial Taman Nasional Bromo Tengger Semeru (TNBTS) dengan ketinggian sekitar $\pm 2.150 \mathrm{mdpl}$ (Malangkabgoid, 2015), sebagian besar 
masyarakat bekerja sebagai petani yang mata pencahariannya adalah bercocok tanam dikarenakan topografi Desa Ngadas sendiri adalah pegunungan (PemkabMalang, 2015). Bekerja sebagai petani adalah pilihan utama bagi masyarakat Ngadas untuk mencukupi kebutuhan hidup sehari-hari, hasil pertanian yang menjadi komoditi unggulan desa ini adalah kubis, kentang dan bawang prei (Trilaksono, 2015). Karakteristik masyarakat Ngadas masih memegang teguh kegiatan tradisi upacara adat yang diturunkan oleh nenek moyang mereka (Sayektiningsih dkk. 2008)

Desa Ngadas merupakan salah satu wilayah yang juga diwarisi pengetahuan mengenai pengobatan secara tradisional dengan memanfaatkan tumbuhan obat. Tumbuhan yang berpotensi sebagai obat cukup banyak, diperoleh sebanyak 45 jenis yang terdiri atas Herba 33 jenis dan Lignosus 12 jenis (Guswika dkk, 2016). Berdasarkan hasil eksplorasi yang dilakukan ditemukan beberapa tanaman di lingkungan sekitar contohnya adas, ajeran, akasia duri, anting-anting, alang-alang, patikan kebo, pegagan, semanggi gunung, kersen, krisan, kecubung gunung, tempuyung, dan masih banyak lagi. Namun, pengetahuan masyarakat mengenai tumbuhan obat sudah mulai luntur. Sebagian besar masyarakat tidak mengetahui jenis-jenis tumbuhan yang dapat dimanfaatkan sebagai obat (Guswika dkk., 2016).

Rendahnya pengetahuan masyarakat desa Ngadas mengenai tumbuhan obat disebabkan informasi yang memadai mengenai berbagai jenis tumbuhan yang dapat digunakan sebagai pengobatan penyakit tertentu dan cara pemanfaatannya belum terdokumentasi dengan baik. Salah satu upaya dalam membangun keterbatasan pengetahuan dapat dilakukan dengan kegiatan penyuluhan.

Penyuluhan merupakan pendidikan nonformal yang mengacu pada programprogram yang dirancang oleh suatu lembaga atau pemerintah untuk memenuhi kebutuhan masyarakat pedesaan (Roberts, 2016). Dalam melakukan penyuluhan sebagai bentuk pendidikan berkelanjutan seorang penyuluh harus memahami konsep dari proses penyuluhan tersebut, adapun proses penyuluhan terdiri atas 5 tahap sebagai berikut (Jitendra, 2007):

1) studi situasi dan masalah: pada tahap ini penyuluh harus mengumpulkan semua informasi tentang masyarakat sekitar yang akan menerima penyuluhan yang berkaitan dengan pendidikan, ekonomi, usaha, dan mata pencaharian. Kemudian penyuluh harus menganalisis semua masalah yang terjadi dan menentukan faktor dasarnya,

2) Tujuan dan solusi: menentukan tujuan penyuluhan, yang mana tujuan tersebut harus sesuai dengan kebutuhan masyarakat. Tujuan tersebut harus disertakan dengan solusi yang harus dapat membawa perubahan kearah lebih baik sesuai dengan yang diinginkan,

3) Menyusun rencana penyuluhan: pada tahap ini penyuluh harus memikirkan bagaimana penyuluhan akan dilakukan, metode apa yang akan digunakan, dan apa saja yang dibutuhkan untuk kegiatan penyuluhan,

4) Evaluasi: pada tahap ini penyuluhan telah dilakukan, dan harus ada evaluasi untuk melihat apakah cara yang kita pilih sudah benar serta apak solusi yang kita tawarkan diterima dengan baik atau tidak. Sukses tidaknya suatu kegiatan penyuluhan dapat terlihat dari evaluasi,

5) Peninjauan kembali: jika hasil evaluasi menunjukkan bahwa tujuan dari penyuluhan tidak terpenuhi maka harus dilakukan penyuluhan kembali dan pekerjaan diulangi mulai dari tahap pertama lagi.

Istilah penyuluhan juga dipakai secara luas yang dalam artian secara umum sebagai proses penyebarluasan informasi untuk membantu suatu individu atau 
masyarakat agar terwujudnya perubahan yang lebih baik sesuai dengan yang diharapkan (Kusnadi, 2011). Penyuluhan mempunyai peran penting dalam membantu masyarakat agar dapat mengatasi permasalahan yang dihadapi (Sadono, 2008).

Tujuan dari penulisan artikel ini adalah untuk mengkaji potensi dari penyuluhan sebagai upaya dalam meningkatkan pengetahuan masyarakat. Kajian pada tulisan ini merupakan studi literatur dari berbagai jurnal terbaru yang ada hubungannya dengan penyuluhan dalam meningkatkan pengetahuan. Penelitian ini terdiri dari data primer dan data sekunder. Data primer merupakan data pengetahuan masyarakat yang diperoleh dengan menggunakan angket dan wawancara lansung mengenai tumbuhan obat. Data sekunder berasal dari studi pustaka yang dilakukan dengan cara mengkaji dari beberapa hasil penelitian terdahulu mengenai upaya penyuluhan dalam meningkatkan pengetahuan masyarakat. Analisis data dilakukan secara deskriptif kuantitatif dari hasil angket dan wawancara.

\section{SOLUSI/TEKNOLOGI}

Solusi yang ditawarkan dalam memecahkan permasalahan mengenai keterbatasan pengetahuan yang dimiliki masyarakat desa Ngadas mengenai tumbuhan obat adalah melakukan penyuluhan dengan menggunakan buku pintar tumbuhan obat yang didesain semenarik mungkin untuk meningkatkan minat masyarakat dalam membacanya. Buku tersebut berisikan hasil eksplorasi lapangan mengenai tumbuhan obat yang terdapat disekitar desa Ngadas. Adapun penyuluhan yang akan dilakukan ditargetkan kepada masyarakat Ngadas khususnya IbuIbu PKK dan masyarakat dengan status sosial ekonomi menengah kebawah. Kegiatan penyuluhan akan dilakukan sebanyak 3 kali pertemuan dengan melakukan tes sumatif disetiap akhir pertemuan.

\section{HASIL DAN DISKUSI}

Berdasarkan hasil sebaran angket yang dilakukan untuk melihat pengetahuan masyarakat desa Ngadas mengenai tumbuhan obat diperoleh persentase secara keseluruhan pengetahuan masyarakat mengenai tumbuhan obat sebesar $53.5 \%$ dengan kategori kurang baik atau rendah. Rendahnya pengetahuan masyarakat mengenai tumbuhan obat salah satunya disebabkan oleh kurangnya informasi yang memadai mengenai jenis-jeni tumbuhan di lingkungan sekitar yang dapat dimanfaatkan sebagai obat (Guswika dkk, 2016). Berdasarkan hasil wawancara terhadap masyarakat, penyuluhan mengenai penggunaan tumbuhan obat sudah pernah dilakukan dengan teknik ceramah mengenai manfaat tumbuhan obat dengan bantuan media Powerpoint yang ditayangkan kepada masyarakat. Selain itu, penyuluhan dengan menggunakan brosur yang dibagikan kepada masyarakat tentang tumbuhan obat akan tetapi tidak secara berkelanjutan dan tumbuhan yang ditampilkan sebagain besar tidak ada di sekitar desa Ngadas, oleh karena itu masyarakat desa Ngadas setuju dan mendukung adanya kegiatan penyuluhan kembali mengenai tumbuhan obat dengan menggunakan buku tumbuhan obat yang dikembangkan dari hasil penelitian eksplorasi, sebagai salah satu cara penyebaran informasi mengenai potensi tumbuhan obat yang terdapat di desa Ngadas. Seperti yang dikemukakan oleh Amanah (2007) bahwa Kegiatan penyuluhan harus mengutamakan kebutuhan partisipan dan bersifat berkelanjutan.

Rendahnya pengetahuan masyarakat Ngadas mengenai tumbuhan obat berdampak pada sikap masyarakat yang. Berdasarkan hasil pengamantan lapangan, hampir seluruh pekarangan rumah masyarakat desa Ngadas tidak ada yang memiliki tumbuhan obat. Pengetahuan 
merupakan hal yang sangat penting dalam mempengaruhi tindakan dan menentukan sikap (Dapudong, 2014). sikap atau perilaku individu sangat bergantung pada apa yang individu tersebut ketahui, yang mana sikap merupakan kombinasi dari beberapa hal penting seperti kepribadian, keyakinan, milai-nilai, perilaku dan motivasi (Pickens, 2005). Suatu sikap yang sering mengasah pengetahuan yang dimiliki dapat mempertahankan pengetahuan tersebut dalam jangka panjang (Mansouri, dkk. 2009).

Masyarakat Ngadas memiliki status social ekonomi yang masih tergolong kelas menengah kebawah, oleh karena itu dengan adanya kegiatan penyuluhan mengenai tumbuhan obat ini dapat dijadikan salah satu wirausaha dalam meningkatkan penghasilan masyarakat setempat serta sebagai upaya budidaya tumbuhan obat. Sebagai mana yang dijelaskan oleh Peraturan menteri pertanian (2013) bahwa kegiatan penyuluhan mampu untuk mengorganisasikan suatu usaha sebagai upaya meningkatkan produktivitas, efisiensi, pendapatan dan kesejahteraan serta meningkatkan kesadaran dalam pelestarian fungsi lingkungan hidup.

Penyuluhan merupakan proses yang dilakukan untuk penyebarluasan informasi, motivasi, komunikasi dan edukasi yang dilakukan baik secara lisan maupun tulisan kepada suatu individu, kelompok maupun massal (Permensos, 2014), dengan pemberian perhatian dalam membangun keterbatasan pengetahuan serta membangun kepercayaan antara penyuluh dengan audiensinya (Klerkx dkk., 2016).

Penyuluhan dan pendidikan memiliki keterkaitan yang mana penyuluhan merupakan salah satu bentuk tugas dari praktik kependidikan (FAO, 2015), terdapat partisipan atau peserta didik dan guru atau penyuluh (Shaun, 2013), bersifat pembelajaran dua arah yang mana guru atau penyuluh juga ikut belajar, fleksibel, berdasarkan kebutuhan masyarakat dan pendidikan yang bersifat berkelanjutan (Shaun, 2013), yang berfungsi sebagai upaya untuk mengembangkan berbagai aspek pengetahuan (Rivera, 2001), serta membangun pengetahuan yang telah ada agar terciptanya suatu sikap baru untuk memecahkan masalah yang ada (FAO, 2015).

Tujuan dari kegiatan penyuluhan adalah memberi informasi sebagai upaya pemecahan masalah yang terjadi (Agriinfo, 2015). Selain itu sebagai kegiatan transfer ilmu pengetahuan dan keterampilan, sarana teknis dan informasi, menumbuhkan rasa percaya diri dan motivasi (FAO, 2015). Beberapa tujuan penting lainnya seperti mengubah perilaku masyarakat agar dapat lebih baik (better farming), berusaha tani lebih menguntungkan (better business), hidup lebih sejahtera (better living) dan hidup bermasyarakat lebih baik (better community) (Kusnadi, 2011). Berikut ini adalah tabel 1. Beberapa artikel mengenai penyuluhan yang telah berhasil meningkatkan pengetahuan masyarakat:

Tabel 1. Beberapa artikel terkait mengenai penyuluhan dalam meningkatkan pengetahuan

\begin{tabular}{|c|c|c|c|}
\hline No & Nama \& Tahun & Deskripsi Penelitian & Hasil \\
\hline 1 & $\begin{array}{l}\text { Signh \& Oliver } \\
(2014)\end{array}$ & $\begin{array}{l}\text { Berdasarkan penelitian yang } \\
\text { dilakukan oleh penyuluhan } \\
\text { mengenai praktek-praktek } \\
\text { pertanian } \\
\text { berkelanjutan secara } \\
\text { meningkatkan pengetahuan } \\
\text { masyarakat yang pada Setelah } \\
\text { diberikan penyuluhan }\end{array}$ & $\begin{array}{l}\text { total keseluruhan persentase } \\
\text { pengetahuan lelaki dan perempuan } \\
\text { sebelum penyuluhan sebesar } 55 \% \\
\text { yang memiliki pengetahuan rendah. } \\
\text { Setelah mendapatkan penyuluhan } \\
\text { mengalami perbedaan yang } \\
\text { signifikan dengan persentasi petani } \\
\text { laki-laki yang memiliki pengetahuan }\end{array}$ \\
\hline
\end{tabular}




\begin{tabular}{|c|c|c|c|}
\hline & & & $\begin{array}{l}\text { rendah menurun menjadi } 31,28 \% \text { dan } \\
\text { untuk petani perempuan menurun } \\
\text { menjadi } 33,96 \% \text {. }\end{array}$ \\
\hline 2 & $\begin{array}{l}\text { Mathiasen } \\
\text { dkk.(2012) }\end{array}$ & $\begin{array}{l}\text { Penelitian yang dilakukan } \\
\text { mengenai penyuluhan untuk } \\
\text { meningkatkan pemahaman } 50 \\
\text { orang pekerja pertanian } \\
\text { terhadap keamanan pangan }\end{array}$ & $\begin{array}{l}\text { Sebelum penyuluhan persentase } \\
\text { pemahaman pekerja sebesar } 59,3 \% \text {, } \\
\text { Setelah mendapatkan penyuluhan } \\
\text { meningkat menjadi } 60,7 \% \text {. }\end{array}$ \\
\hline 3 & Taye (2013) & $\begin{array}{l}\text { Melakukan analisis terhadap } \\
\text { artikel dampak penyuluhan } \\
\text { pada } 10 \text { negara yaitu Kenya, } \\
\text { Somalia, Pantai Gading, } \\
\text { Rwanda, Burkina Faso, } \\
\text { Uganda, Zimbabwe, } \\
\text { Mozambik, Ethiopia, dan } \\
\text { Tanzania }\end{array}$ & $\begin{array}{l}\text { Hasil penelitian ini menunjukkan } \\
\text { kegiatan penyuluhan memiliki } \\
\text { dampak yang positif dalam } \\
\text { membentuk pengetahuan masyarakat } \\
\text { dengan persentase sebesar } 71 \%\end{array}$ \\
\hline 4 & $\begin{array}{l}\text { Arshed } \\
(2012)\end{array}$ & $\begin{array}{l}\text { Meneliti tentang upaya } \\
\text { penyuluhan yang paling baik } \\
\text { dalam } \\
\text { penyetahuan petani jagung } \\
\text { mengenai produksi jagung di } \\
\text { Pakistan. Dengan pilihan } \\
\text { pertemuan langsung seperti } \\
\text { diskusi } \\
\text { pembelajaran, kelompok, demonstrasi } \\
\text { serta teknik lain seperti } \\
\text { melalui telepon, radio dan tv }\end{array}$ & $\begin{array}{l}\text { Hasil penelitian menunjukkan bahwa } \\
\text { penyuluhan yang lebih efektif adalah } \\
\text { pertemuan secara langsung dengan } \\
\text { persentase masing-masing diskusi } \\
\text { kelompok sebesar } 43.3 \% \text {, } \\
\text { pembelajaran } 42,6 \% \text { dan demonstrasi } \\
40,9 \%\end{array}$ \\
\hline 5 & $\begin{array}{l}\text { Godtland dkk } \\
\text { (2004) }\end{array}$ & $\begin{array}{l}\text { Melakukan evaluasi denagn } \\
\text { melakukan survei terhadap } \\
\text { dampak penyuluhan pertanian } \\
\text { tentang pengelolaan hama } \\
\text { dalam budidaya kentang } \\
\text { terhadap petani di peru } \\
\text { dengan membandingkan } \\
\text { petani yang ikut berpartisipasi } \\
\text { dalam program penyuluhan } \\
\text { dengan petani yang tidak ikut } \\
\text { program penyuluhan }\end{array}$ & $\begin{array}{l}\text { Hasil penelitian menunjukkan } \\
\text { perbedaan yang signifikan bahwa } \\
\text { petani yang ikut berpartisipasi dalam } \\
\text { program penyuluhan memiliki } \\
\text { pengetahuan yang lebih banyak } \\
\text { dibandingkan petani yang tidak ikut } \\
\text { dalam penyuluhan }\end{array}$ \\
\hline 6 & $\begin{array}{l}\text { Cerdan } \\
(2008)\end{array}$ & $\begin{array}{lrr}\text { Melakukan } & \text { penelitian } \\
\text { mengenai saran } & \text { dalam } \\
\text { produksi anggur meliputi } & \text { purian } \\
\text { pembuatan irigasi, pemberian } \\
\text { pupuk dan } & \text { teknik } \\
\text { pemangkasan pada petani } \\
\text { argentina. Dengan sampel } \\
\text { peserta penyuluhan dan } \\
\text { anggota produsen anggur } \\
\text { lainnya yang ingin ikut } \\
\text { berpartisipasi }\end{array}$ & $\begin{array}{l}\text { Penyuluhan yang dilakukan } \\
\text { berdampak positif terhadap hasil dan } \\
\text { kualitas produksi anggur yang } \\
\text { terdapat di argentina }\end{array}$ \\
\hline 7 & Khan \& Iqubal & Melakukan $\quad$ pelatihan & Penyuluhan \\
\hline
\end{tabular}




\begin{tabular}{|c|c|c|c|}
\hline & (2005) & 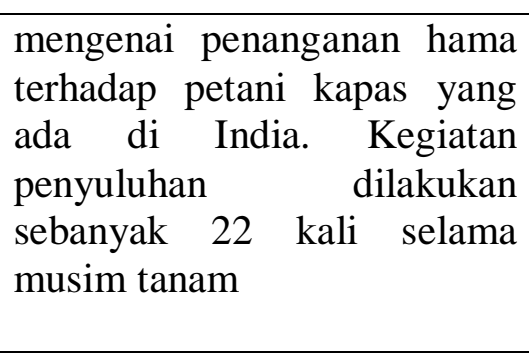 & $\begin{array}{l}\text { berdampak terhadap pengetahuan, } \\
\text { keyakinan dan pengambilan } \\
\text { keputusan petani kapas dalam } \\
\text { menggunakan pestisida. Selain itu } \\
\text { juga berdampak pada produktivitas } \\
\text { dan pendapatan yang diperoleh } \\
\text { petani kapas di India. }\end{array}$ \\
\hline 8 & Kumba (2003) & $\begin{array}{l}\text { Mengkaji tentang partisipasi } \\
\text { petani dalam penelitian } \\
\text { pertanian di Namibia dengan } \\
\text { mengkaji dokumentasi } \\
\text { program pertanian dari tahun } \\
\text { 1999-2001 }\end{array}$ & $\begin{array}{l}\text { Dari hasil kajian yang dilakukan } \\
\text { dirasa sangat perlu dilakukan } \\
\text { penyuluhan untuk menekankan peran } \\
\text { aktif petani dalam penelitian } \\
\text { dibidang pertanian yang mana } \\
\text { kegiatan penyuluhan ini dipandang } \\
\text { akan menguntungkan petani juga } \\
\text { sebagai penambahan pengetahuan } \\
\text { dalam memperbaharui keterampilan } \\
\text { serta menangani kesulitan yang } \\
\text { terjadi di lapangan }\end{array}$ \\
\hline 9 & $\begin{array}{l}\text { Norsida } \\
\text { (2016) }\end{array}$ & $\begin{array}{l}\text { Penelitian ini untuk menguji } \\
\text { kebutuhan penyuluhan di } \\
\text { bidang pertanian terhadap } \\
300 \text { responden masyarakat } \\
\text { Irak dari berbagai kalangan } \\
\text { professional klien, konsultan } \\
\text { dan kontraktor. }\end{array}$ & $\begin{array}{l}\text { dari hasil penelitian yang dilakukan } \\
\text { di peroleh hasil bahwa penyuluhan di } \\
\text { bidang pertanian sangat dibutuhkan } \\
\text { oleh masyarakat irak }\end{array}$ \\
\hline 10 & Tesfaye (2010) & $\begin{array}{l}\text { Penelitian ini untuk menguji } \\
\text { kefektifan dari penyuluhan } \\
\text { pertanian yang dilakukan oleh } \\
\text { Ethiopian Institute of } \\
\text { Agricultural Research } \\
\text { (EIAR) dalam meningkatkan } \\
\text { pengetahuan dan sikap petani } \\
\text { di Ethiopia, dengan } \\
\text { melakukan wawancara secara } \\
\text { terbuka terhadap } 40 \text { petani } \\
\text { dari petani yang telah } \\
\text { menerima penyuluhan dan } 40 \\
\text { petani yang tidak menerima } \\
\text { penyuluhan. }\end{array}$ & $\begin{array}{l}\text { Hasil penelitian yang di analisis } \\
\text { dengan menggunan hitungan chi- } \\
\text { square dan t-test menunjukkan } \\
\text { penyuluhan yang dilakukan oleh } \\
\text { Ethiopian Institute of Agricultural } \\
\text { Research (EIAR) secara signifikan } \\
\text { telah meningkatkan pengetahuan } \\
\text { petani yang telah menerima } \\
\text { penyuluhan mengenai penanaman } \\
\text { kentang,bawang dan gandum serta } \\
\text { sikap praktek petani yang terlatih } \\
\text { dibandingkan petani yang tidak } \\
\text { menerima penyuluhan. }\end{array}$ \\
\hline
\end{tabular}

Berdasarkan beberapa artikel yang telah dikaji menunjukkan bahwa penyuluhan merupakan salah satu upaya yang efektif dalam meningkatkan dan membangun pengetahuan di masyarakat. Hal ini dikarenakan penyuluhan merupakan pendidikan non formal lebih diarahkan untuk masyarakat pedesaan yang menawarkan saran dan informasi untuk membantu memecahkan permasalahan mereka (FAO, 2015).

Keuntungan penerapan penyuluhan untuk tujuan mendidik yaitu dapat memberikan contoh nyata dan relevan serta memberikan gambaran mengenai pelatihan kerja di lapangan (WBOED, 1999). Hal ini menunjukkan penyuluhan menjadi upaya yang baik dalam meningkatkan pemahaman masyarakat (Okeke dkk., 2015), dengan cara 
memberikan informasi mendasar secara luas untuk merangsang keinginan masyarakat berbuat lebih baik (Anderson dkk., 2004), selain itu untuk membantu dalam melakukan inovasi, meningkatkan hasil pertanian dan taraf hidup masyarakat, dan membantu masyarakat dalam progresif lebih baik (Shaun, 2013).

\section{KESIMPULAN}

Berdasarkan kajian yang dilakukan penyuluhan menjadi upaya yang tepat dan perlu dilakukan dalam meningkatkan dan mempertahankan pengetahuan masyarakat mengenai tumbuhan obat. Saran untuk kedepannya perlu untuk dilakukan penyuluhan dengan menggunakan buku hasil pendokumentasian tumbuhan yang ditemukan di desa Ngadas untuk memberikan informasi mengenai potensi tumbuhan obat yang terdapat di desa Ngadas.

\section{UCAPAN TERIMA KASIH}

Ucapan terima kasih diberikan kepada Kepala desa Ngadas yang telah memberikan izin untuk melakukan penelitian di desa Ngadas. Masyarakat desa Ngadas yang telah ikut berpartisipasi selama kegiatan penelitian tahap awal berlangsung. Balai konservasi Taman Nasional Bromo Tengger Semeru yang telah memberikan izin untuk memasuki wilayah hutan selama proses eksplorasi tumbuhan obat. Serta temanteman satu tim yang telah membantu selama dilapangan.

\section{PUSTAKA}

Agriinfo. 2015. Extension Education. (online), (http://www.agriinfo.in/ default.aspx ? page $=$ topic $\&$ superid $=$ 7\&topicid=1436), diakses pada tanggal 9 November 2016

Anderson, J.R., \& Gershon, F. 2004. Agricultural Extention: Good Intentions and Hard Realities. The
World Bank Research Observer, 19(1):41-60

Amanah, S. 2007. Makna penyuluhan dan transformasi perilaku manusia. Jurnal penyuluhan, 3(1):63-67

Arshed, A. W., Khalid M. C., Muhammad I., \& Altaf H. 2012. Effectiveness of extension education methods used by Rafhan Maize Products for information dissemination to maize growers of Central. Pakistan Journal of Food Sciences, 22(1):36-39.

Cerdan, P.I., Alessandro M., Diego U. 2008. The Impact of Agricultural Extension Services: The Case of Grape Production in Argentina (abstract). (online), (https://ideas.repec.org/p/idb/ovewps /0508.html\#author-body), diakses pada tanggal 13 November 2016

Dapudong, R. C. 2014. Teachers' Knowledge and Attitude towards Inclusive

Education: Basis for an Enhanced Professional Development Program. International Journal of Learning \& Development, 4(4):1-24

FAO. 2015. Understanding extention. (online), (http://www.fao.org/docrep/t0060e/ T0060E03.htm), diakses pada tanggal 18 Agustus 2016.

Guswika, H., Sri E.I., Suhadi. 2016. Kajian Tumbuhan Obat Di Daerah Enclave (Desa Ngadas) Taman Nasional Bromo Tengger Semeru. Artikel disampaikan di Seminar Nasional ke-3 \& Workshop Biologi, IPA, dan pembelajarannya, Universitas Negeri Malang, 15 Oktober 2016

Godtland, E.M., Elisabeth S., Alain D.J., Rinku M., \& Oscar O. 2004. The Impact of Farmer Field Schools on Knowledge and Productivity: A Study of Potato Farmers in the Peruvian Andes. Economic development and Cultural Change, 53(1):63-92

Jitendra, C. 2007. Agricultural Extension Education. 
(http://nsdl.niscair.res. in/ jspui/bitstream/123456789/307/1/A GRICULTURAL EXTENSION EDUCATION.pdf), diakses pada tanggal 19 agustus 2016.

Khan, M. A. \& Iqubal, M. 2005. Sustainable Cotton Production through Skill Development among Farmers: Evidence from Khaipur District of Sindh, Pakistan. The Pakistan Development Review, 44(4):695716.

Klerkx, L., Landini, F. \& Santoyo-Cortés, H., 2016. Agricultural extension in Latin America: current dynamics of pluralistic advisory systems in heterogeneous contexts. The Journal of Agricultural Education and Extension, 22(5):389-397.

Kumba, F.F., 2003. Farmer Participation in Agricultural Research and Extension Service in Namibia. Journal of International Agricultural and Extension Education, 10(3):47-55

Kusnadi, D. 2011. Dasar-dasar Penyuluhan Pertanian. (online), (http://stppbogor.ac.id/userfiles/

file/Modul\%20Dasar\%20Penyuluha n\%20(DK).pdf), diakses pada tanggal 6 agustus 2016.

Malangkabgoid. 2015. Desa wisata ngadas, poncokusumo. (online), (http://www.malangkab.go. $\mathrm{id} / \mathrm{site} / \mathrm{read} /$ detail/296/desa-wisatangadas-poncokusumo.html), diakses pada tanggal 24 Mei 2016.

Mansouri, N., Banafsheh, G., Seyed, V.S., Jafar, B., Reza, Y.N., Afarin, R. M., \& Narges, A. 2009. The change in attitude and knowledge of health care personnel and general population following trainings provided during integration of mental health in Primary Health Care in Iran: a systematic review. International Journal of Mental Health Systems, 3(1):7-15

Norsida,B.M., Jasmin M.S., Salim H., Falah H.Z., Nolila M.N., Sulaiman U. 2016. Training Needs of Agricultural
Extension Agents Using Borich Needs Assessment Model. Asian Journal of Agricultural Extension, Economics \& Sociology, 13(1):1-19

Mathiasen, L., katija M., Benjamin C., Douglas P., 2012. Using a Training Video to Improve Agricultural Workers' Knowledge of On-Farm Food Safety. Journal of Extension, 50(1)

Okeke, M.N., Hyacinth, U.N., Uzuegbunan, C.O. 2015. Emerging Role of Information Communication Technologies in Extension Service Delivery in Nigeria: A Review. Journal of Agricultural Extension, 19(1):128-141

Pemkab malang. 2015. Desa Wisata Ngadas, Poncokusumo. (Online), (http://www.malangkab.go.id/site/re ad/detail/296/desa-wisata-ngadasponcokusumo.html), diakses pada tanggal 24 Mei 2016.

Peraturan Menteri Pertanian. 2013. Pedoman Pembinaan kelompok Tani dan Gabungan Kelompok Tani. (online), (http://perundangan. pertanian.go.id/admin/ file/ Permentan\%20No.82\%20Tahun\%20 2013.pdf), diakses pada tanggal 6 Agustus 2016.

Permensos. 2014. Penyuluhan Sosial. (online),

(http://www.bphn.go.id/data/

documents/

permensos_10_tahun_2014.pdf), diakses pada tanggal 9 Agustus 2016.

Pickens, J. 2005. Attitudes and Perceptions. Organizational Behavior in Health Care, 43-75.

Roberts, N. 2016. The Difference Between Agricultural Education and Extension, and Why It Matters. (online), (https://agrilinks.org/blog /difference-between-agriculturaleducation-and-extension-and-why-itmatters), diakses pada tanggal 9 November 2016 
Sadono, D. 2008. Pemberdayaan petani: paradigm baru penyuluhan pertanian di Indonesia. Jurnal penyuluhan, 4(1):66-74

Sayektiningsih, T., Resti M., Harini M. 2008. Strategi Pengembangan Pendidikan Konservasi Pada Masyarakat Suku Tengger Di Desa Enclave Taman Nasional Bromo Tengger Semeru. Media Konservasi, 13(1): 32-37

Shaun, K. (2013). Extension Education: Meaning, Features and Principles. (online),

(http://www.biologydiscussion.com/ agriculture/extension-educationmeaning-features-and-principlesagricultural-extension/24130), diakses pada tanggal 19 Agustus 2016.

Singh, S., \& Oliver, H. 2014. Impact of extension education on improving knowledge of sustainable technical agricultural practices. Agric Eng Int: CIGR Journal, 16(1):198-206.

Taye, H. 2014. Evaluating the impact of agricultural extension programmes in sub-Saharan Africa: Challenges and prospects. African Evaluation Journal, 1(1):1-9

Tesyafe, T., Ranjan S.K., Tekluk T. 2010. Farmers training effectiveness in terms of changes in knowledge and attitude: The case of Holeta, Melkassa and Debre zeit Agricultural Research Centres, Ethiopia. Journal of Agricultural Extension and Rural Development, 2(5):89-96

Trilaksono, E.P. 2015. Eksplorasi Karakteristik Pembangunan Ekonomi Desa Melalui Unsur-Unsur Budaya Universal di Desa Ngadas Kecamatan Poncokusumo Kabupaten Malang. JESP, 7(2):7377

WBOED. 1999. Agricultural Extension The Kenya Experience. (online), (http://lnweb90.worldbank.org/oed/o eddoclib.nsf/docunidviewforjavasear $\mathrm{ch} / \mathrm{b} 728 \mathrm{~d} 887 \mathrm{fc} 2 \mathrm{~b} 754 \mathrm{~d} 852568 \mathrm{bd005a}$ 8c19/\$file/198precis.pdf), diakses pada tanggal 20 oktober 2016 